\title{
Drosophila mechanoreceptors as a model for studying asymmetric cell division
}

\author{
DAGMARA P. FURMAN ${ }^{*, 1,2}$ and TATYANA A. BUKHARINA ${ }^{1}$ \\ ${ }^{1}$ Institute of Cytology and Genetics, Siberian Branch, Russian Academy of Sciences, Novosibirsk and \\ ${ }^{2}$ Novosibirsk State University, Novosibirsk, Russia
}

\begin{abstract}
Asymmetric cell division (ACD) is one of the processes creating the overall diversity of cell types in multicellular organisms. The essence of this process is that the daughter cells exit from it being different from both the parental cell and one another in their ability to further differentiation and specialization. The large bristles (macrochaetae) that are regularly arranged on the surface of the Drosophila adult function as mechanoreceptors, and since their development requires ACD, they have been extensively used as a model system for studying the genetic control of this process. Each macrochaete is composed of four specialized cells, the progeny resulting from several ACDs from a single sensory organ precursor (SOP) cell, which differentiates from the ectodermal cells of the wing imaginal disc in the third-instar larva and pupa. In this paper we review the experimental data on the genes and their products controlling the ACDs of the SOP cell and its daughter cells, and their further specialization. We discuss the main mechanisms determining the time when the cell enters ACD, as well as the mechanisms providing for the structural characteristics of asymmetric division, namely, polar distribution of protein determinants (Numb and Neuralized), orientation of the division spindle relative to these determinants, and unequal segregation of the determinants specifying the direction of daughter cell development.
\end{abstract}

KEY WORDS: selector gene, Drosophila, macrochaetae, sensory organ precursor cell, signaling pathway

\section{Introduction}

Asymmetric cell division (ACD) is a process that, on the one hand, provides for self-maintenance and self-renewal of cell populations and, on the other, determines the possibility of differentiation of structure and function between cells in a population. Differing only in details, ACD occurs in a wide range of taxa in both the plant and animal kingdoms, thereby suggesting its evolutionary conservation (Knoblich, 2008; Abrash, Bergmann, 2009). In populations of unicellular organisms, this process provides for the diversity of cell types, which optimizes the existence of population as a whole (Lawler, Brun, 2006), and in multicellular organisms, it is a basic process in development of organs and tissues (Knoblich, 2008; Abrash, Bergmann, 2009).

In multicellular organisms, the abnormalities of ACD regulation in adult stem cells lead to tumorigenesis (Graham et al. 2010; Hyenne et al., 2010; Powell et al., 2010). In particular, it has been shown that the development of Drosophila brain tumors is associated with abnormalities in ACD and/or the imbalance between asymmetric and symmetric divisions as well as development of leukemia and skin cancer in mammals and colorectal tumors in humans (Caussinus, Gonzalez, 2005; Lechler, Fuchs 2005; Congdon, Reya, 2008; Quyn et al., 2010).

The necessary and sufficient conditions for ACD are a polarized distribution of certain proteins (protein determinants) and some RNAs in the parental cell and an accurate positioning of the division spindle relative to these determinants. An asymmetric mitosis leads to unequal segregation of determinants between the daughter cells and predetermines the difference in their further fates.

Traditional objects for studying the asymmetric division are plant meristems, D.melanogaster neuroblasts and germline stem cells, cells of $C$. elegans early embryos, and the adult stem cells of humans and other mammals (Seery, Watt, 2000; Zhang et al., 2003; Lechler, Fuchs, 2005; Gaziova, Bhat, 2007; Gonczy, 2008; Abrash, Bergmann, 2009). In addition, components of the Droso-

Abbreviations used in this paper: ACD, asymmetric cell division; AS-C, achaetescute complex; SOP, sensory organ precursor cell; WID, wing imaginal disc.

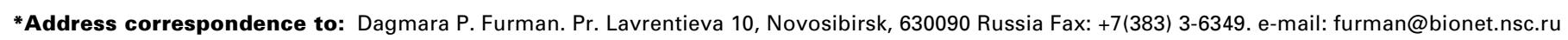




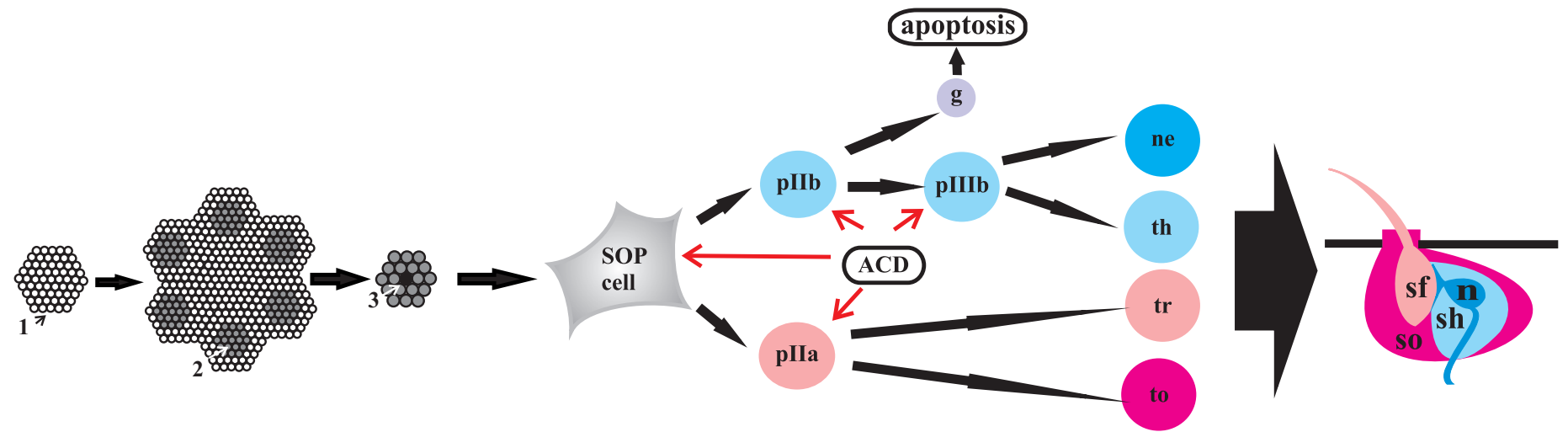

Fig. 1. Scheme of the morphogenesis of the bristle organ. (1) ectodermal cells of the wing imaginal disc; (2) proneural cluster (dark gray); (3) proneural cluster with the single SOP cell in its center; plla, pllb, and plllb are the daughter cells; (g) glial cell, which undergoes apoptosis; (ne) neuron; (th) thecogen; (tr) trichogen; (to) tormogen; (sf) shaft; (so) socket; (sh) sheath; and (n) bipolar neuron. Pink scale denotes the cuticular structures of mechanoreceptor and blue scale, the neural structures.

phila nervous system-sensory organs, i.e., macrochaetae-are an adequate and traditional model for such studies. The four specialized cells composing the sensory organ originate from a single cell-the so-called sensory organ precursor (SOP) cellvia four successive asymmetric divisions. This model has made it possible to extend our knowledge about the structural and functional characteristics of ACD.

The this paper we review the experimental data on the main genes and their products involved in the processes of ACD and specialization of daughter cells in the development of mechanoreceptor. We consider the conditions necessary for these processes and the mechanisms of their regulation, namely, the time of SOP cell entry into division, polarization of cells with respect to
A
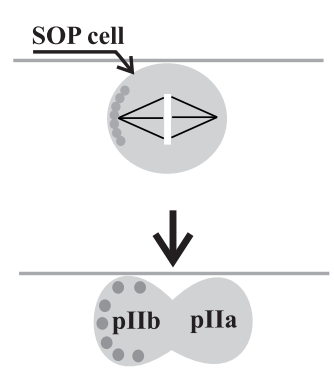

C

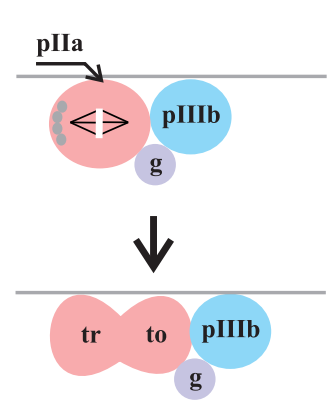

B
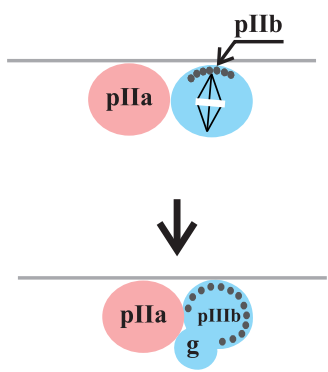

D

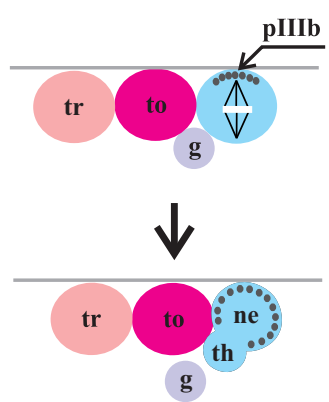

Fig. 2. Two types of ACD in the morphogenesis of mechanoreceptors. (A,C) $a-p$ type and (B,D) $a-b$ type. Dark gray and light gray dots inside the cells are protein determinants. The abbreviations are as in Fig. 1. Horizontal line shows the plane of the wing imaginal disc. Pink and blue scales denote the same structures as in Fig. 1. the localization of protein determinants, segregation of determinants between the daughter cells, and the role of selector genes in controlling the production of ACDs determinants and other important products.

\section{Morphogenesis of macrochaetae: general information}

Macrochaetae as elements of the Drosophila peripheral nervous system perform a mechanoreceptor function. The sensory organ consists of the external part, visible on the surface of imago's body - the shaft and socket, and the neural elements per se, hidden in the body-the bipolar neuron and sheath. The morphogenesis of macrochaetae takes about $55 \mathrm{~h}$ at the stage of Drosophila late larva and early pupa (Campuzano, Modolell, 1992). This is a three-stage process, involving several dozens of genes.

At the first stage, the so-called proneural clusters-groups of 20-30 cells - are formed in the layer of uniform ectodermal cells that constitutes the wing and other imaginal discs. At the second stage, a single cell, the Sensory Organ Precursor or SOP cell, is selected from each proneural cluster to develop the mechanoreceptor. The final stage comprises three successive ACDs of the SOP cell, which provides the spatial diversity for further specialization of the progeny cells (Fig. 1). Correspondingly, four daughter cells-trichogen, tormogen, neuron, and thecogen-are formed from each SOP cell. Two of them (trichogen and tormogen) later give the cuticular part of mechanoreceptor. The two remaining cells give its neural component-the glial sheath and the bipolar neuron.

The first ACD of the SOP cell predetermines the different fates of its daughter cells plla and pllb: in the next division, plla gives rise to trichogen and tormogen, while pllb is predetermined to neural specialization and after asymmetric mitosis gives the plllb cell and a small glial cell. Soon after formation, the glial cell undergoes apoptosis, while plllb after asymmetric mitosis forms the neuron and thecogen.

Thus, the key events in the morphogenesis of macrochaetae are the determination of SOP cell and successive ACDs of this cells and its progeny. The mechanisms of SOP cell determination were reviewed earlier (Furman, Bukharina, 2008), so here we will focus on the molecular genetic mechanisms of ACD. 


\section{Asymmetric division as a basic specialization process of the mechanoreceptor cells}

\section{Types of ACD in the Drosophila neurogenesis}

The two associated characteristic features of ACD are the cell polarization with respect to location of certain proteins, referred to as protein determinants, and orientation of the division spindle relative to these determinants. According to these features, the ACDs taking place in development of the Drosophila nervous system fall into two types corresponding to the polarization types of dividing cell (Fig. 2).

The first type is the so-called a-p (anterior-posterior) or SOP cell type, observed in the division of SOP and plla cells. This is: the axis of the distribution of protein determinants and the spindle orientation coincide with the cell anterior-posterior axis of the tissue. The spindle is symmetric; the centrosomes retain their size and shape during the entire mitosis; and the daughter cells formed by cytokinesis are of approximately equal sizes. The plane of cell division is perpendicular to the plane of imaginal disc epithelium, and when separated, the daughter cells remain in the same plane as the imaginal disc epithelium and parental cell (Fig. $2 \mathrm{~A}, \mathrm{C}$ )

The second type is the so-called a-b (apical-basal) or neuroblast type of division, seen in the pllb and plllb cells during morphogenesis of the mechanoreceptor (Fig. 2 B, D). In this case, the axes of the distribution of protein determinants and the spindle are perpendicular to the plane of the disc epithelium, while the plane of division is parallel to the disc plane (Roegiers et al., 2001). Prior to this type of division, the apical centrosome increases in size and the microtubules aggregating around it elongate and form a conspicuous cap in the apical part of the cell. In contrast, the basal centrosome is smaller and the microtubules associated with it are shorter then with the apical centrosome. These differences lead to an asymmetry of the spindle in anaphase and, as a consequence, a shift in the cleavage furrow and differences in between the daughter cells. The daughter cells are localized to the plane perpendicular to the disc plane (Roegiers et al., 2001).

The genes controlling ACD and daughter cell specialization About thirty genes are involved in the genetic control of ACD and

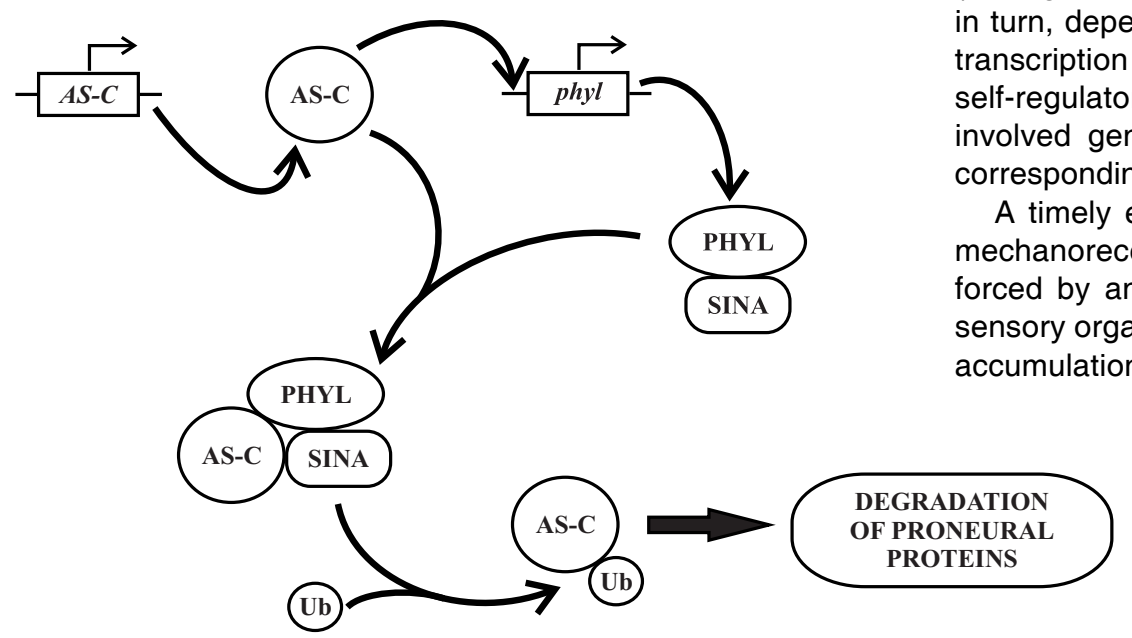

Fig. 3. Interaction of the proneural proteins AS-C with the adaptor protein Phyllopod (PHYL) and E3 ubiquitin ligase Seven-in-absentia (SINA); Ub, ubiquitin. the specialization of daughter cells. They can be divided into the following groups:

1. The genes involved in the regulation of ACD:

- The genes regulating the time of cell entry into mitosis (phyllopod, seven-in-absentia, cdc2, and String);

- the genes encoding asymmetrically localized protein determinants (neuralized and numb);

- the genes providing for polarization of the dividing cell, including:

--the genes required for the first polarization phase ( frizzled, prickle, dishevelled, Van Gogh, and flamingo);

--the genes required for the second polarization phase

(inscuteable, bazooka, par-6, atypical protein kinase $C$, partner of inscuteable, partner of numb, and shotgun); and - The genes required for spindle orientation (genes of $G$ protein subunits and pins); and

2. The selector genes (tramtrack, musashi, miranda, staufen, prospero, cut, bereft and Bar)controlling the subsequent further specialization of the progeny cells.

Below, we consider each ACD stage and specialization of the progeny cells and the role of the listed genes and their products in more detail.

\section{The time of SOP cell entry into mitosis}

The main characteristic of the SOP cell, which distinguishes it from the remaining cells of the imaginal disc, is an increased content of the proneural proteins Achaete and Scute, encoded by gene complex achaete-scute (AS-C). Artificial prolongation of G2 phase and delay of mitosis are associated with accumulation of these proteins (Negre et al., 2003). To switch to division, the cell requires a decrease in their concentration, which determines the possibility of mechanoreceptor development (Chang etal., 2008).

The proneural proteins are degraded by the ubiquitination complex, containing the adaptor protein Phyllopod (PHYL) and the E3 ubiquitin ligase Seven-in-absentia (SINA). PHYL binds to proneural proteins to allow the ligase to attach ubiquitin to them, initiating their degradation in ptoteasomes (Fig. 3).

The lifespan of proneural proteins and, thereby, the duration of premitotic phase, is determined by the rate of $\mathrm{PHYL}$ accumulation (Chang et al., 2008), while the expression of the gene phyllopod, in turn, depends on the proneural AS-C proteins, which act as transcription factors to initiate its expression (Pi et al., 2004). The self-regulatory feedback loop coordinates the expression of the volved genes and the balance in the accumulation of the rresponding proteins.

A timely entry of the SOP cell into mitosis is important for mechanoreceptor development: when the beginning of division is orced by an excess of the mitotic inducer String (STG), the y organ does not develop at all (Negre et al., 2003). STG which is the signal for beginning of mitosis, results from transcriptional activation of stg and is connected with a decrease in the concentration of ASC proneural proteins (Chang et al., 2008).

Along with the listed factors, the time of parental cell entry into ACD is also regulated by other cell cycle proteins, in particular, the cyclin-dependent kinase Cdc2. A forced increase in the activity of this protein leads to fate transformation the SOP cell, which adopts the fate of its daughter cell pllb; 
consequently, an abnormal mechanoreceptor consisting of only neuron and its sheath is formed (Fichelson, Gho, 2004).

\section{Protein determinants of $A C D$}

An obligate characteristic of the cell undergoing ACD is an asymmetric distribution of specific protein determinants. Numb and Neuralized (NEUR), membrane associated proteins that concentrate at one of the cell poles in late prophase, are the main determinants. After asymmetric division, the daughter cells differ in their contents of Numb and NEUR due to an asymmetric segregation of these proteins into one of them (Fig. 4) (Le Borgne, Schweisguth, 2003; Le Borgne et al. 2005).

The role of Numb and NEUR in rendering cells able to differentiate in a certain direction is determined by their involvement in the Notch signaling pathway, which is the main intercellular mechanism providing for the establishment of such ability.

In addition to these proteins, Sanpodo (SPDO) and endocytosis proteins, including Dynamin (DYN) and $\alpha$-Adaptin, are also involved in Notch signaling regulation. The scheme of Notch signaling is shown in Fig. 5.

The ubiquitin ligase NEUR and DYN are responsible for internalization of the ligand Delta (DI) and maintain an inductive state of the signaling cell. The internalization is performed by endocytosis, where both the ligand alone and in complex with intracellular Notch domain can undergo endocytosis. It is assumed that the internalized ligand matures in endosomes followed exposure of the mature species on the cell membrane

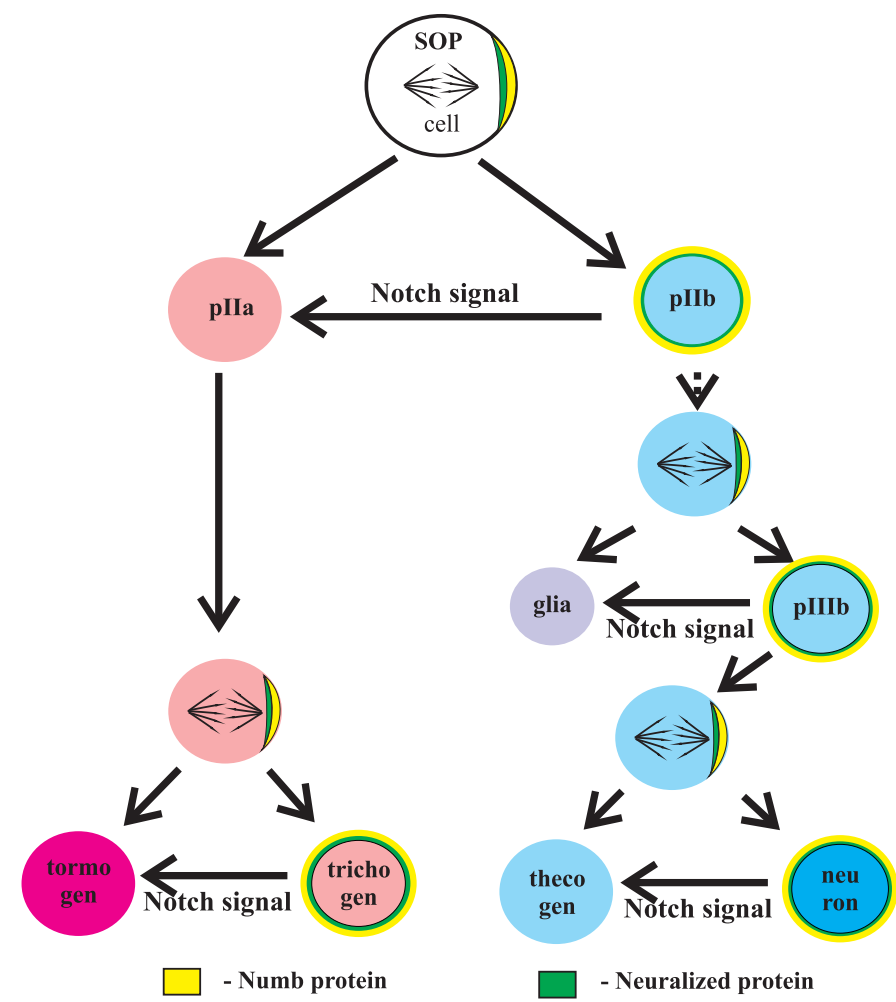

Fig. 4. The distribution of Numb and Neuralized proteins in ACD of the SOP cell and its daughter cells and the direction of Notch signal transduction between the sister cells. Pink and blue scales denote the same structures as in Fig. 1. surface (Le Borgne et al., 2005) (Fig. 5, I). The function of DYN is in the cleavage of the endosome with transported proteins from the cell membrane (Seugnet et al., 1997).

Internalization of the complex frees the sites for new ligand molecules on the membrane of an inducer cell, thereby providing for formation of new ligand-receptor complexes and prolonging an inductive state of the cell (Le Borgne et al., 2005) (Fig. 5, II).

Numb regulates the direction of Notch signaling via endocytosis of the proteins $\mathrm{N}$ and SPDO (Fig. 5, III). The cell with internalized $\mathrm{N}$ and SPDO will be the source of signal. The adaptor protein $\alpha$-Adaptin is involved in endocytosis together with Numb (Le Borgne et al., 2005; Hutterer, Knoblich, 2005).

Recently, a motif was identified in the SPDO structure that provides for its direct binding to Numb. This finding supports the hypothesis that Numb regulates the SPDO trafficking and Notch signaling independently (Tong et al., 2010).

Thus, the cell having acquired both Numb and NEUR as a result of ACD functions as a source of signal, while the cell lacking these proteins, as a receiver of Notch signals.

Consequently, these two cells express different sets of genes, which, in turn, leads to different directions in their differentiation (Le Borgne, Schweisguth, 2003; Le Borgne et al., 2005; Cau, Blader, 2009). In the morphogenesis of mechanoreceptor, the daughter cell that received Numb and NEUR (pllb) after SOP division follows a neural specialization pathway and gives the neuron and thecogen after the next division. The absence of these determinants in the second cell, plla, which is a receiver of the Notch signal, deprives it of the possibility to further differentiate into the neural parts of mechanoreceptor, so it produces the trichogen and tormogen after the next division (Fig. 4) (Le Borgne, Schweisguth, 2003).

\section{Establishment of a polarized localization of protein determi- nants and orientation of the mitotic spindle}

The cell polarization with respect to the localization of the protein determinants Numb and NEUR and the associated spindle orientation are mandatory attributes of the ACD. These processes are of fundamental importance, because they determine the fate of the daughter cell and the possibility of normal mechanoreceptor development.

Initially Numb and NEUR are symmetrically localized in the parental cell, just as in the surrounding cells of imaginal disc.

The protein determinants polarize with the help of specific protein complexes formed at the cell poles (Bellaiche et al., 2004). However, the molecular mechanisms underlying asymmetric localization of the protein determinants are still rather poorly understood.

In the case of Numb the localization of protein determinants in the SPO cell is established in two phases. The first phase, associated with the establishment of anterior-posterior cell polarization, is common for all the cells of the imaginal disc. The major role here is played by the intercellular interaction between the SOP cell and surrounding cells, which accumulate at their membranes two types of protein complexes. The complexes of the first type comprise two transmembrane proteins-Frizzled (FZ) and Flamingo (FMI) - and one membrane protein, Dishevelled (DSH). The second type is formed by two transmembrane proteins-Van Gogh (VANG) or Strabismus (STBM) and Flamingo (FMI)-and the membrane protein Prickle (PK) (Bellaiche et al., 2004). The 


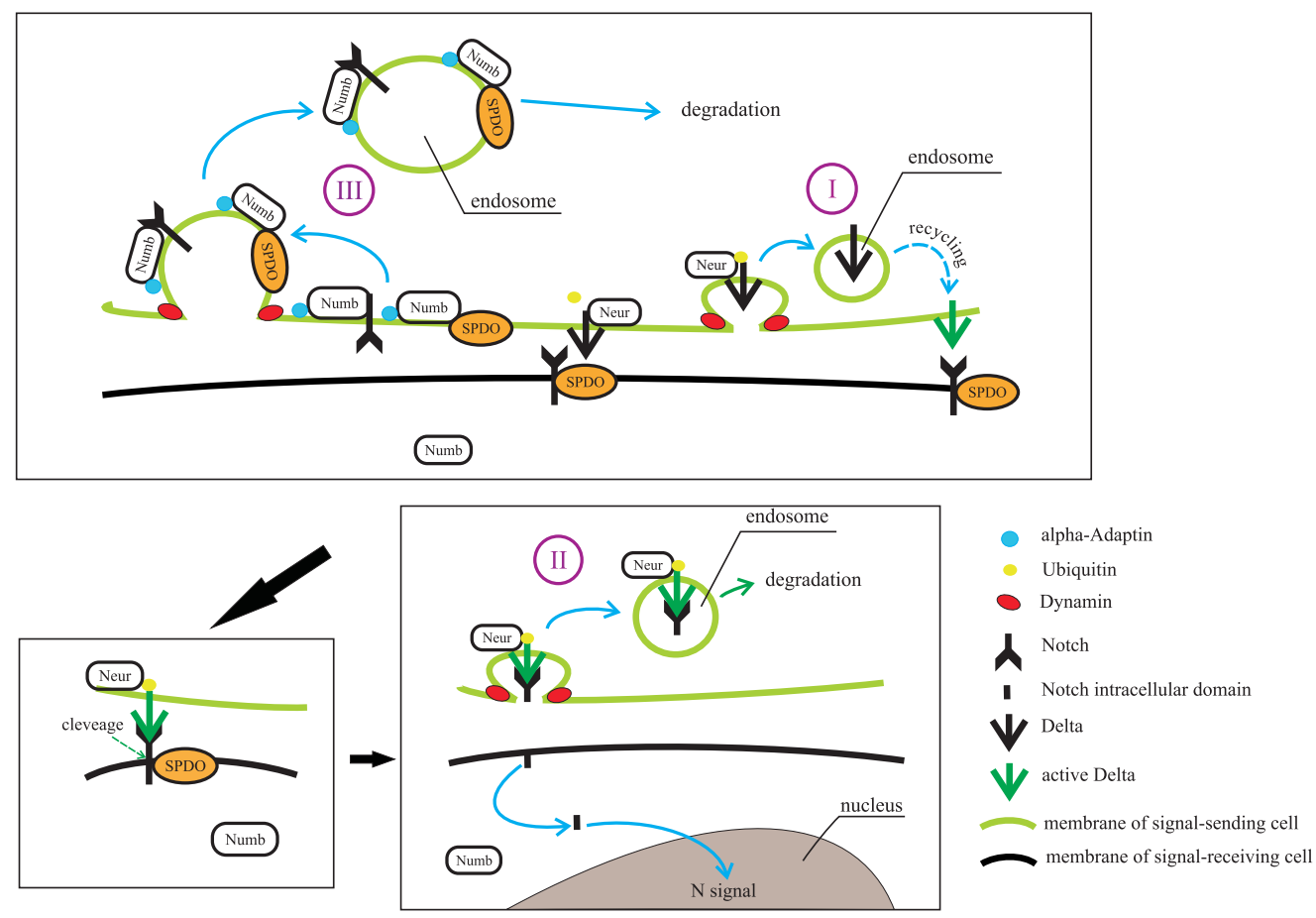

Fig. 5. The regulation of Notch signal transduction between the sister cells produced by an asymmetric cell division (see text for details).

complex of the first type belonging to a cell of the SOP neighborhood is recognized by the complex of the second type, and vice versa; thus, these complexes cross-interact.

Consequently, the complex containing FZ appears at the one pole of the SOP cell and the complex containing VANG, at the other (Fig. 6). A polarized localization of these proteins ends the first phase in establishment of the SOP cell polarity (Bellaïche $e t$ al., 2004).

As has been earlier demonstrated, the cell proceeds to the second phase of polarization via the interaction of the first phase proteins FZ, VANG, PK, and DSH with two second phase complexes. The first complex consists of atypical protein kinase $C$ (aPKC), Bazooka (Par-3), and Par-6 (Bazooka/Par-6/aPKC) and the second, of Partner of Inscutable (PINS), Discs-large (DLG), and $\alpha$-subunit of G-protein (DLG/PINS/Gai) (Fig. 7). In this process, VANG promotes the localization of PINS at the same pole where it is located itself, while the protein DSH acts antagonistically to VANG by removing PINS from the pole where it is located (Bellaiche et al., 2004).

The second phase in polarization of the SOP cell is determined by intracellular events that either preserve or redetermine the initially established polarity. During this phase, the protein determinants are strictly positioned in the SOP cell; in particular, Numb, earlier uniformly spread over the inner membrane surface, is positioned at one of the poles, and this finally determines the type of polarization.

This process involves the adaptor protein Partner of Numb (PON), Lethal(2) giant larvae (LGL), PINS, and the proteins of Par and $\mathrm{G}$ complexes. LGL and the Par complex probably play the main role in Numb positioning (Roegiers et al., 2001).

The Par complex is localized to only one pole in the SOP cell as well as in the plla, pllb, and plllb cells. Moreover, this complex is never detectable together with Numb, which colocalizes with PON and nonphosphorylated LGL (WirtzPeitz et al., 2008).

The localization of Par complex in the SOP, plla, pllb, and plllb cells is determined by the polarization specified at the first phase by the FZ and VANG distribution and depends on the presence or absence of the protein Inscuteable (INSC). In pllb and plllb cells, containing INSC, the assembly site for the Par complex is changed, thereby redetermining the cell polarization from an $a-p$ to an $a-b$ type. The SOP and plla cells, lacking this protein, retain an $a-p$ polarization type (Bellaiche et al., 2001).

The second phase of polarization is provided by the cascade phosphorylation with involvement of the complex Par-6/LGL/aPKC, associated with the membrane at one of the cell poles (Wirtz-Peitz et al., 2008) (Fig. 8).

The cascade is triggered by phosphorylation of Par- 6 within the complex by the Aurora-A kinase (AURA) (Fig. 8, A). This leads to activation of aPKC, which, in turn, phosphorylates one of its targets, LGL (Fig. 8, B). The LGL phosphorylation leads to intramolecular interaction between its $\mathrm{N}$ and C-ends; consequently, LGL loses the ability to bind to both the actin cytoskeleton and other proteins and is inactivated (Betschinger etal., 2005; Wirtz-Peitz etal., 2008). The inactivated
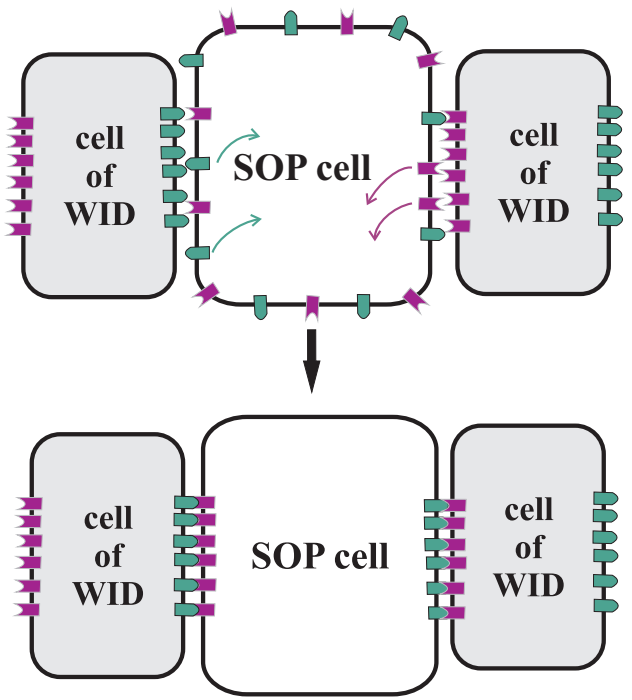

- protein complexes containing Frizzled
- - protein complexes containing Van Gogh

Fig. 6. Primary polarity establishment in the sensory organ precursor (SOP) cell. WID, wing imaginal disc. 

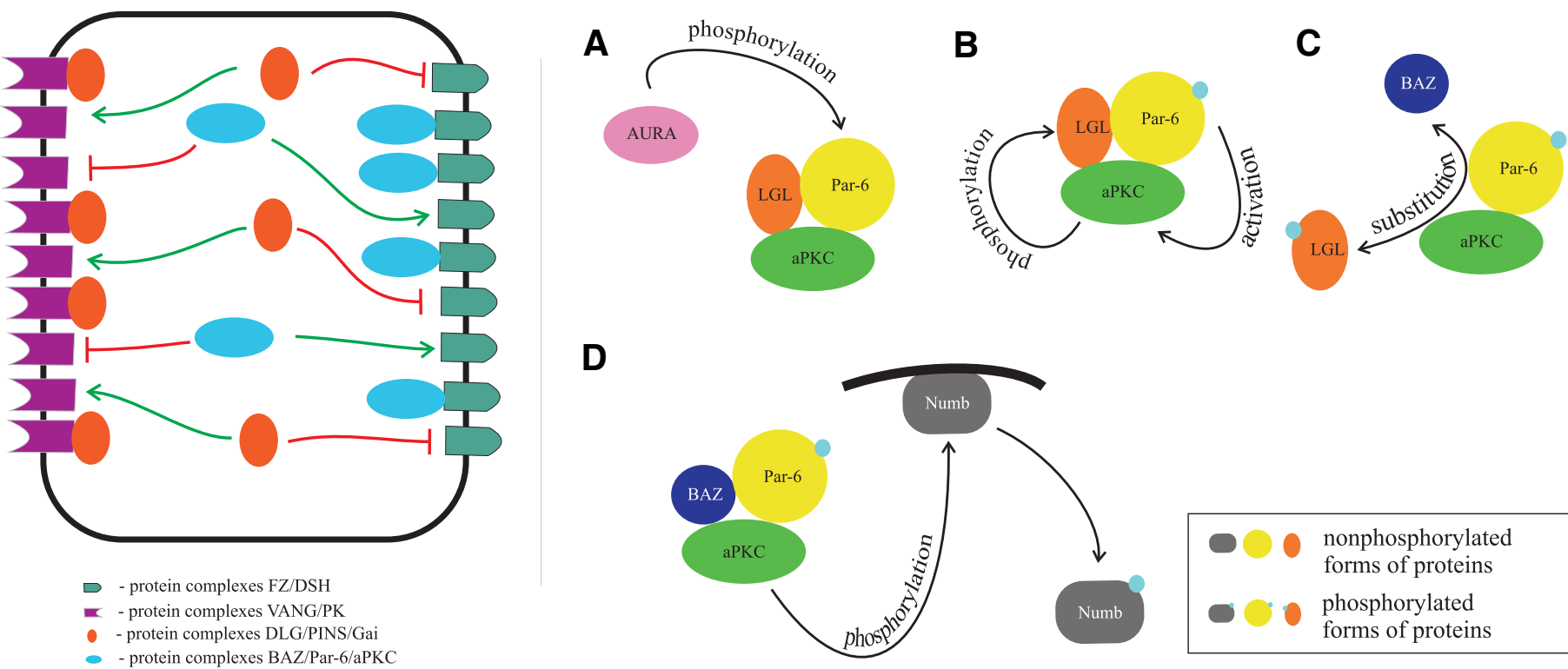

D

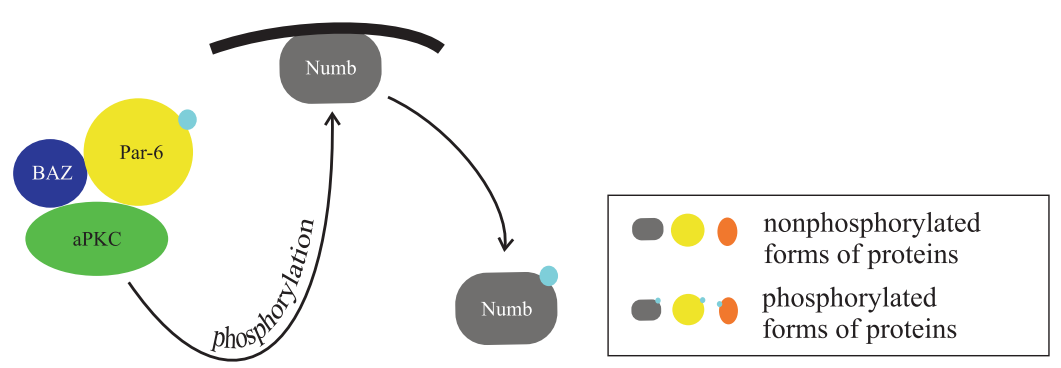

Fig. 7 (left). The scheme of interaction between the proteins involved in the first and second phases of sensory organ precursor cell polarization. Green arrows show that interaction between complexes is possible and red arrows, that interaction is impossible.

Fig. 8 (right). Cascade protein phosphorylation during the second phase of cell polarization. Phosphorylated protein species are denoted with blue circles.

LGL leaves the LGL/Par-6/aPKC complex, where the protein Bazooka replaces it (Fig. 8, C). At the second stage, the Par complex, owing to this substitution, acquires the ability to recognize the Numb protein, colocalized on the cell membrane, and aPKC becomes able to phosphorylate it. The phosphorylated Numb form loses the contact with the membrane and migrates to the cytoplasm (Wirtz-Peitz et al., 2008) (Fig. 8, D).

Thus, AURA is the key positive regulator of an asymmetric Numb distribution. The complex Protein Phosphatase 2A (PP2A), dephosphorylating Par-6 within the Par complex (Ogawa et al., 2009), acts as a negative regulator. The dephosphorylation excludes the possibility of aPKC activation, thereby blocking the triggering of subsequent stages in phosphorylation cascade (Fig. 9). The balance of positive and negative regulations of the cascade provides for establishing and maintaining a polar Numb distribution and asymmetry of cell division.

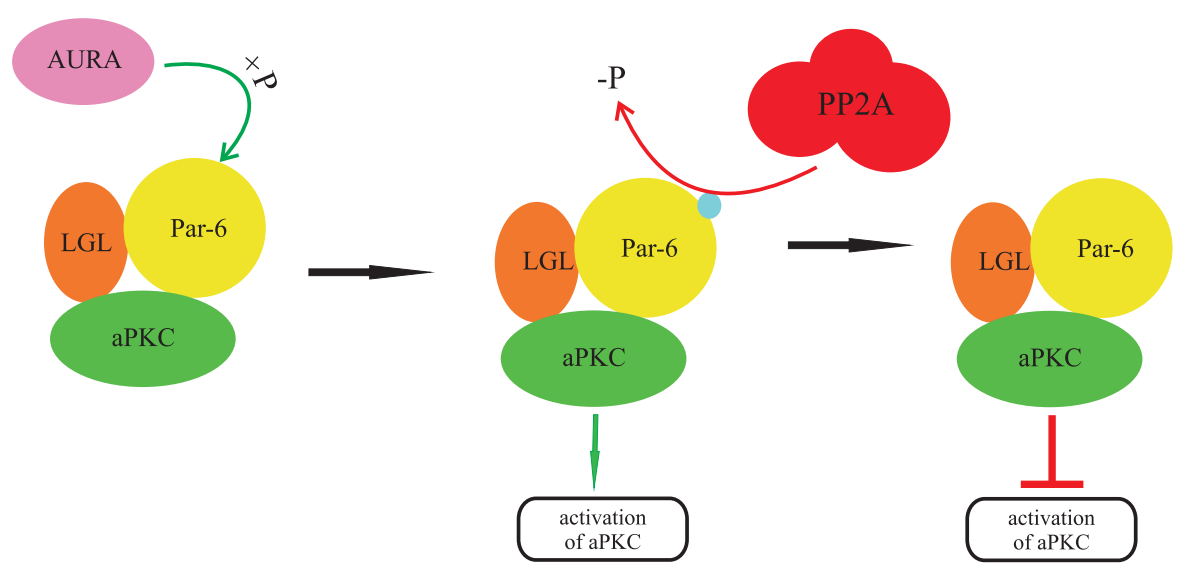

Fig. 9. Positive and negative regulations of aPKC activation.
A polarity in the location of Numb is specified by localization of the Par complex. The presence of the Par complex at one of the cell poles provides for the subsequent Numb phosphorylation and detachment from the membrane of Numb and/or the PON/Numb complex. Consequently, this pole becomes free of Numb. Concurrently, no Numb phosphorylation takes place on the other pole, which lacks the Par complex, and Numb remains bound to the membrane.

Along with LGL, the nonmuscle myosin II is involved as a mediator in the Numb positioning: LGL binds to its heavy chain. It is known that myosin II influences the Numb distribution in the cell, although the precise mechanisms of this phenomenon are unclear (Barros et al., 2003; Betschinger et al., 2005). Thus, independently of a particular mechanism, the positioning of Numb and Par complex are mutually exclusive.

Further fixation of the Numb polar localization takes place in the SOP and plla cells with involvement of $G$ protein. $G$ protein is a heterotrimer comprising large $\alpha$-subunit and two smaller $\beta$ - and $\gamma$ subunits; note that the bond between $\alpha$-subunit and the dimer $\mathrm{G} \beta \gamma$ is weaker than that between the subunits of the dimer. The overall complex binds to the polarly localized Frizzled protein via $\mathrm{G} \beta \gamma$, which provides for its localization to only one cell pole. Then, $\alpha-$ subunit interacts with PINS and detaches from the heterotrimer, thereby producing the dimer Goi/PINS. Forming the complex with nonphosphorylated LGL and Numb, the dimer fixes Numb at the pole (Schaefer et al., 2000; Schaefer et al., 2001).

At the second phase, the other obligatory characteristic of an ACD-orientation of the 
spindle with respect to the polarly distributed protein determinants, in particular, Numb-is also established. The main player in this process is the Gai/PINS complex, which specifies the point of spindle formation (Roegiers et al., 2001; Bowman et al., 2006). The Par complex also influences the spindle development, determining the degree of its shift towards one of the poles. Consequently, the daughter cell that inherited the Par complex during division is larger as compared with the sister cell. This difference can be insignificant in the case of an a-p type of ACD or considerable, as in the case of an a-b type (Roegiers et al., 2001; Betschinger et al., 2004).

The spindle orientation during division of plla cells depends on DE-Cadherin (CAD), encoded by the shotgun (shg) gene. A precise mechanism of the DE-Cadherin action is yet unknown. It has been shown that this protein is contained in the DE-Cadherin/ Catenin complex, which forms a large block at the sites of contact of pllb-plla and plllb-plla cells. Presumably, this particular protein is involved in the determination of spindle orientation (Le Borgne et al., 2002).

Thus, the second phase in polarization of the dividing cells ends with formation of the protein complexes allowing for Numb concentration at one of the poles and the spindle oriented relative to Numb (Bellaiche et al., 2001; Roegiers et al., 2001).

These processes provides for ACD in each generation of parental cells, thereby predetermining the fates of daughter cells.

\section{Selector genes and the directions of daughter cell differen- tiation}

The direction of daughter cell development depends on the combination of the selector genes tramtrack, musashi, prospero, miranda, staufen, bereft, Bar, etc., expressed in the cells, and the "selector" functions of these genes can be implemented at both protein and mRNA levels. The products of strictly specific selector genes are detected in the cells of neural and cuticular specialization.

The gene $t$ tk codes for a transcription factor whose determined targets are achaete, asense, and deadpan (Badenhorst et al., 2002). After the first SOP cell division, the ttkmRNA is detectable in both daughter cells in approximately equal amounts; however, the TTK protein is detected in plla and is undetectable in pllb (Fig. $10 \mathrm{~A})$.

The differences in the TTK content are determined by the action of another selector gene, musashi, and that this action is coupled with simultaneous activation of the Notch pathway (Badenhorst et al., 2002). The gene msi codes for a nuclear protein capable of specifically binding to 3'-UTR of ttk mRNA, thereby prohibiting its translation. After the first SOP cell division, the protein $\mathrm{MSI}$ is detectable in both daughter cells, however, the ttk mRNA is translated only in one of them. The observed effect is attributed to the signal transduction via the Notch signaling pathway: $\mathrm{MSI}$ is degraded in the plla cell, where this signal transduction is not blocked, and the transcript is freed for translation. In the second daughter cell, pllb, which received Numb as a result of the asymmetric division and where the signal is blocked, the prohibition on translation is retained (Okano et al., 2002) (Fig. $10 \mathrm{~B}, \mathrm{C})$.

The gene prospero encodes a transcription factor that activates expression of the genes achaete, scute, asense, miranda, aPKC, Cyclin E, and others (Choksi et al., 2006). The quantity of PROS protein in the dividing SOP cell is insignificant, and it colocalizes with Numb at one of the poles. PROS marks the cells that follow a neural differentiation pathway. This protein is never found in either plla cell or tormogen and trichogen, whereas it is detectable in pllb and its derivatives (Manning, Doe, 1999) (Fig. 11). Note that the dynamics of the PROS contents in neuron and thecogen are diametrically opposite: it gradually disappears in the neuron and accumulates in the thecogen.

The products of the selector genes staufen and miranda are responsible for the PROS distribution in the pllb cell and its derivatives.

The protein Staufen contains the so-called double-stranded RNA binding domain (dsRBD), via which it can bind to doublestranded RNAs, including the corresponding regions of the Prospero mRNA (Ramos et al., 2000). The protein Miranda is involved in the PROS distribution via formation of the complexes with both PROS itself and the complex Staufen/pros mRNA; Miranda interacts with the latter via the so-called cargo-binding domain, which is a double helix (Yousef et al., 2008). Since MIRA
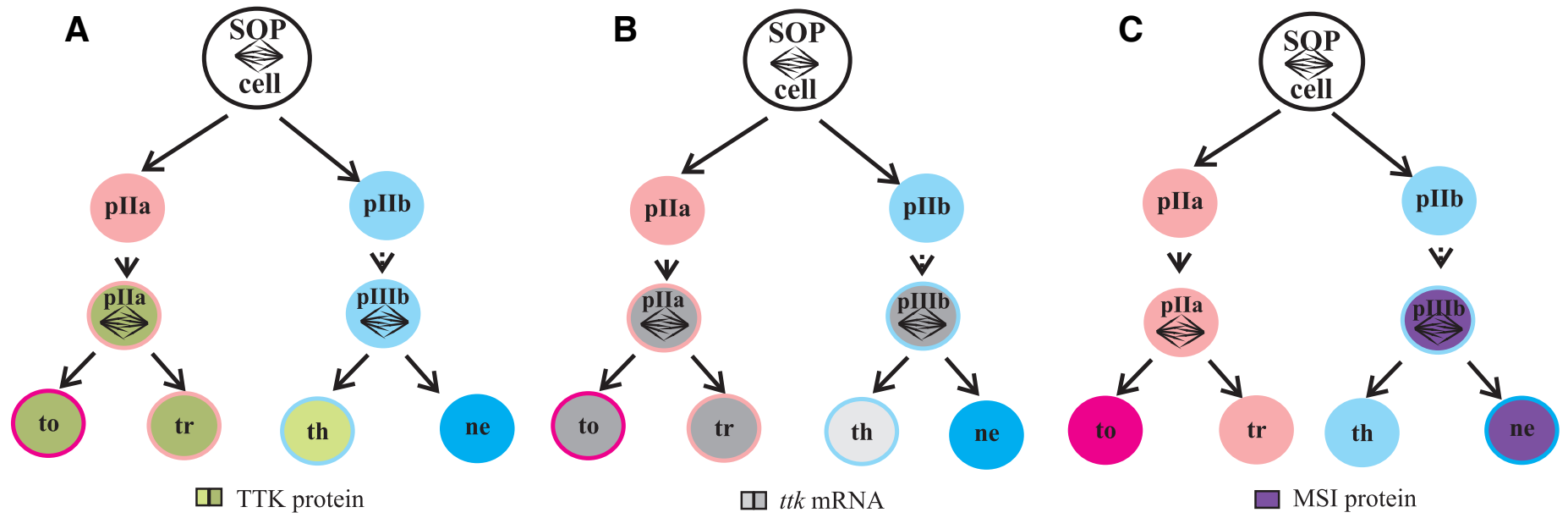

Fig. 10. Distributions of the TTK and MSI proteins and ttk mRNA during asymmetric divisions of the sensory organ precursor (SOP) cell and its daughter cells. (A) TTK, (B) ttk mRNA and (C)MSI. Pink and blue scales denote the same structures as in Fig. 1. Lighter gray and green gradation denote smaller concentrations of ttk mRNA and TTK protein, respectively. The abbreviations are as in Fig. 1. 


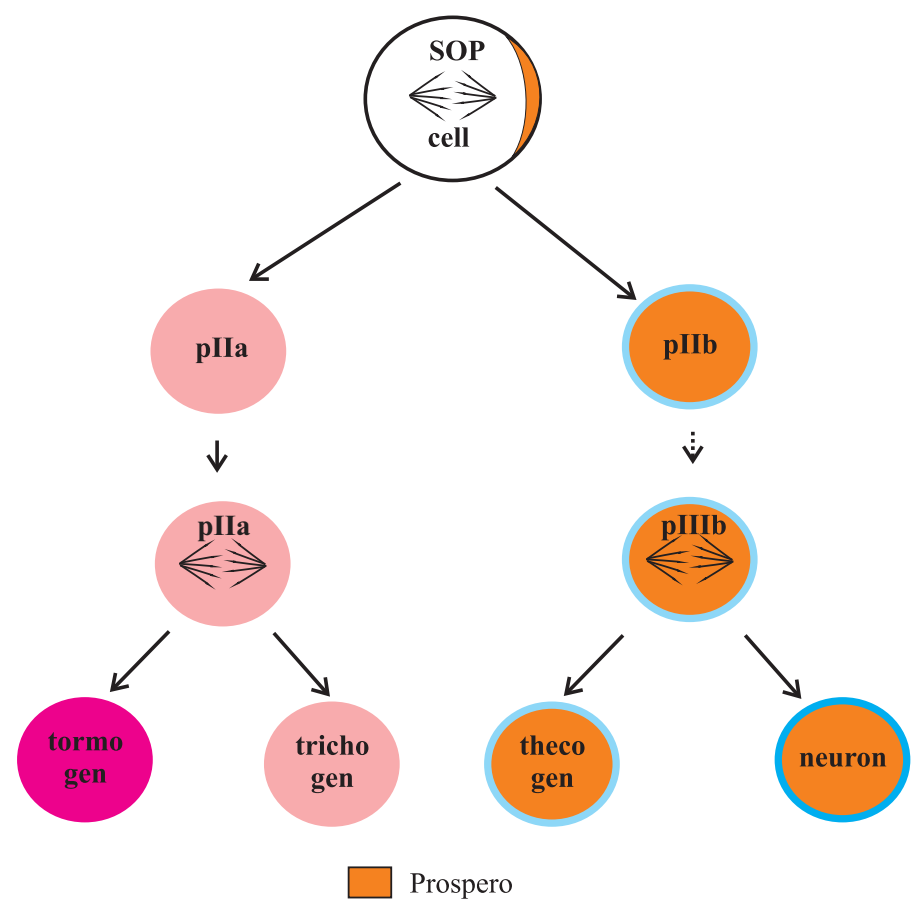

Fig. 11. The localization of Prospero during asymmetric division of the developing bristle organ. Pink and blue scales denote the same structures as in Fig. 1.

concurrently binds to Numb, which is polarly located in the dividing SOP cell, the complexes MIRA/PROS and MIRA/ Staufen/pros mRNA are asymmetrically distributed in it and in a unequal manner in the pllb and its daughter cell (Ramos et al., 2000; Yousef et al., 2008).

In addition to the well-studied selector genes described above, several other genes-cut, bereft (brf), and Bar-are involved in specialization of daughter cells; the functions of these genes have not been sufficiently studied. In particular, it has been shown that the external sensory organs (bristles) are transformed in chordotonal organs in the absence of the cut gene activity (Ebacher et al., 2007). The cut expression is initiated by the proteins of achaete-scute complex. The active transcription is maintained by a feedback autoregulation and continues during the overall differentiation of daughter cells (Vervoort et al., 1995).

The bereft (brf) expression is characteristic of plla, trichogen, and tormogen; however, it is more pronounced in trichogen. The activity of gene bereft depends on the genes ttk and cut; moreover, the Cut protein is able to directly initiate the brf transcription (Hardiman et al., 2002). Unlike brf, the expression of gene Bar is observed only in the neural derivatives of the SOP cell-neuron and thecogen (Sato et al., 1999). Thus, the specialization programs of progeny cells of SOP cell during the sensory organ development are determined by an asymmetric cell division and the activity of selector genes.

\section{Conclusions}

Development of a Drosophilamechanoreceptor is a result of several successive ACDs of a single sensory organ precursor cell and its derivatives. Depending on the presence of the protein Inscuteable in dividing cell and orientation of the polarity axis relative to the surface of the imaginal disc, two types of $A C D$ are identified-the so-called a-p (anterior-posterior) and $a-b$ (apical-basal) types. The conditions determining an ADC are the positioning of specific protein determinants at the cell poles, formation of the cell polarity axis, and orientation of the spindle along this axis. The protein determinants are finally positioned and the polarity axis is determined via formation of the specific protein complexes at the cell poles. The protein complexes localized to the poles specify the initial point for spindle formation. A coordinated progress of these processes provides for an asymmetric pattern of parental cell division, which determines further fates of the progeny cells.

A wide range of studies with various model objects demonstrates an evolutionary conservation of the ACD mechanisms (Goldstein, Macara, 2007). Thus, the results of the studies into the morphogenesis of Drosophila mechanoreceptor are of a general biological character.

Note that the mechanoreceptor is the simplest model for studying ACD. Only several cells are involved in the mechanoreceptor morphogenesis; in addition, an asymmetric type of division for each maternal cell in each generation has no alternative. However, many aspects remain incompletely understood even in such a simple model. For example, the details of the choice between apical-basal and anterior-posterior ACD variants for the SOP cell and the cells following cuticular or neural differentiation pattern are unclear.

The mechanisms underlying the establishment of initial SOP cell polarization connected with the positioning of protein complexes and the protein determinant Neuralized are also not completely understood. Not for all genes, proteins, and protein complexes involved in the asymmetric cell division their precise roles are determined. The situation with another object with characteristic ACD-adult stem cells-is much more intricate. As is known, depending on particular conditions, the cells divide in a symmetric manner in the case of population deficiency and transit to an asymmetric division with the demand to perform their main function as suppliers of cells with certain specialization.

Along with the above listed questions of general character, perhaps, the most important issue arises here-the question on the choice of and switching between the types of division. Since an imbalance between symmetric and asymmetric division types of adult stem cells is among the causes of uncontrolled proliferation, it is evident that the answer to this question is not only of an academic interest, because it will provide for approaching a more complete understanding of the mechanisms underlying the neoplastic growth and give a clue to the control of this process (Powell et al., 2010).

\section{Acknowledgements}

The work was supported by the Presidium of the Russian Academy of Sciences (contract no. 10104-37/-15/110-327/150409-001), the Russian Academy of Sciences (programs 22.8 and 10.7); Siberian Branch of the Russian Academy of Sciences (program "Genomics, Proteomics, and Bioinformatics: Hi-Tech Research into Molecular Biological and Molecular Genetic Systems and Processes" and interdisciplinary integration project no. 119); Federal Agency for Science and Innovations (contract no. 02.512.11.2332) and the RFBR grant no. 09-04-12209-ofi_m. 


\section{References}

ABRASH, E.B., BERGMANN, D.C. (2009). Asymmetric cell divisions: a view from plant development. Dev Cel/ 16: 783-796.

BADENHORST, P., FINCH, J.T., TRAVERS, A.A. (2002) Tramtrack co-operates to prevent inappropriate neural development in Drosophila. Mech Dev117: 87-101.

BARROS, C.S., PHELPS, C.B., BRAND, A.H. (2003) Drosophila nonmuscle myosin II promotes the asymmetric segregation of cell fate determinants by cortical exclusion rather than active transport. Dev Cel/5: 829-840.

BELLAICHE, Y., BEAUDOIN-MASSIANI, O., STUTTEM, I., SCHWEISGUTH, F. (2004) The planar cell polarity protein Strabismus promotes Pins anterior localization during asymmetric division of sensory organ precursor cells in Drosophila. Development 131: 469-478.

BELLAICHE, Y., RADOVIC, A., WOODS, D.F., HOUGH, C.D., PARMENTIER, M.L., O'KANE, C.J., BRYANT, P.J., SCHWEISGUTH, F. (2001) The partner of inscuteable/discs-large complex is required to establish planar polarity during asymmetric cell division in Drosophila. Cel/106: 355-366.

BETSCHINGER, J., EISENHABER, F., KNOBLICH, J. (2005) Phosphorylationinduced autoinhibition regulates the cytoskeletal protein Lethal (2) giant larvae. Curr Bio/ 15: 276-282.

BOWMAN, S.K., NEUMÜLLER, R.A., NOVATCHKOVA, M., DU, Q., KNOBLICH, J.A. (2006) The Drosophila NuMA Homolog Mud regulates spindle orientation in asymmetric cell division. Dev Cel/10: 731-742.

CAMPUZANO, S., MODOLELL, J. (1992) Patterning of the Drosophila nervous system: the achaete-scute gene complex. Trends Genet 8: 202-206.

CAU, E., BLADER, P. (2009) Notch activity in the nervous system: to switch or not switch? Neural Dev 4: 36.

CAUSSINUS, E., GONZALEZ, C. (2005) Induction of tumor growth by altered stemcell asymmetric division in Drosophila Melanogaster. Nat Genet37: 1125-1129.

CHANG, P.J., HSIAO, Y.L., TIEN, A.C., LI, Y.C., PI, H. (2008) Negative-feedback regulation of proneural proteins controls the timing of neural precursor division. Development 135: 3021-3030.

CHOKSI, S.P., SOUTHALL, T.D., BOSSING, T., EDOFF, K., DE WIT, E., FISCHER, B.E., VAN STEENSEL, B., MICKLEM, G., BRAND, A.H. (2006) Prospero acts as a binary switch between self-renewal and differentiation in Drosophilaneural stem cells. Dev Cel/11: 775-789.

CONGDON, K.L., REYA, T. (2008) Divide and conquer: how asymmetric division shapes cell fate in the hematopoietic system. Curr Opin Immuno/20: 302-307.

EBACHER, D.J., TODI, S.V, EBERL, D.F., BOEKHOFF-FALK, G.E. (2007) Cut mutant Drosophila auditory organs differentiate abnormally and degenerate. Fly1: 86-94.

FICHELSON, P., GHO, M. (2004) Mother-daughter precursor cell fate transformation after Cdc2 down-regulation in the Drosophilabristle lineage. Dev Bio/276: 367-377.

FURMAN, D.P., BUKHARINA, T.A. (2008) How Drosophila Melanogasterforms its mechanoreceptors. Curr Genom 9: 312-323.

GAZIOVA, I., BHAT, K.M. (2007) Generating asymmetry: with and without selfrenewal. Prog Mol Subcell Biol45: 143-178.

GOLDSTEIN, B., MACARA, I.G. (2007) The PAR proteins: fundamental players in animal cell polarization. Dev Cel/ 13: 609-622.

GÖNCZY, P. (2008) Mechanisms of asymmetric cell division: flies and worms pave the way. Nat Rev Mol Cell Bio/9: 355-366.

GRAHAM, T.A., JAWAD, N., WRIGHT, N.A. (2010) Spindles losing their bearings: does disruption of orientation in stem cells predict the onset of cancer? Bioessays 32: 468-472.

HARDIMAN, K.E., BREWSTER, R., KHAN, S.M., DEO, M., BODMER, R. (2002) The bereft gene, a potential target of the neural selector gene cut, contributes to bristle morphogenesis. Genetics 161: 231-247.

HUTTERER, A., KNOBLICH, J.A. (2005) Numb and alpha-Adaptin regulate Sanpodo endocytosis to specify cell fate in Drosophila external sensory organs. EMBO Rep 6: 836-842.

HYENNE, V., CHARTIER, N.T., LABBÉ, J.C. (2010) Understanding the role of asymmetric cell division in cancer using C. elegans. Dev Dyn239: 1378-1387.

KNOBLICH, J.A. (2008) Mechanisms of asymmetric stem cell division. Cel/132: 583-597.

LAWLER, M.L., BRUN, Y.V. (2006) A molecular beacon defines bacterial cell asymmetry. Cel/124: 891-893

LE BORGNE, R., BARDIN, A., SCHWEISGUTH, F. (2005) The roles of receptor and ligand endocytosis in regulating Notch signaling. Development132: 1751-1762.

LE BORGNE, R., BELLAÏCHE, Y., SCHWEISGUTH, F. (2002) Drosophila Ecadherin regulates the orientation of asymmetric cell division in the sensory organ lineage. Curr Biol12: 95-104.

LE BORGNE, R., SCHWEISGUTH, F. (2003) Unequal segregation of Neuralized biases Notch activation during asymmetric cell division. Dev Cel/ 5: 139-148.

LECHLER, T., FUCHS, E. (2005) Asymmetric cell divisions promote stratification and differentiation of mammalian skin. Nature 437: 275-280.

MANNING, L., DOE, C.Q. (1999) Prospero distinguishes sibling cell fate without asymmetric localization in the Drosophila adult external sense organ lineage. Development 126: 2063-2071.

NÈGRE, N., GHYSEN, A., MARTINEZ, A.M. (2003) Mitotic G2-arrest is required for neural cell fate determination in Drosophila. Mech Dev 120: 253-265.

OGAWA, H., OHTA, N., MOON, W., MATSUZAKI, F. (2009) Protein phosphatase $2 \mathrm{~A}$ negatively regulates aPKC signaling by modulating phosphorylation of Par6 in Drosophila neuroblast asymmetric divisions. J Cel/ Sci122: 3242-3249.

OKANO, H., IMAI, T., OKABE, M. (2002) Musashi: a translational regulator of cell fate. J Cell Sci115: 1355-1359.

PI, H., HUANG, S.K., TANG, C.Y., SUN, Y.H., CHIEN, C.T. (2004) phyllopod is a target gene of proneural proteins in Drosophila external sensory organ development. Proc Nat/ Acad Sci USA 101: 8378-8383.

POWELL, A.E., SHUNG, C.Y., SAYLOR, K.W., MÜLLENDORFF, K.A., WEISS J.B., WONG, M.H. (2010) Lessons from development: A role for asymmetric stem cell division in cancer. Stem Cell Res 4: 3-9.

QUYN, A.J., APPLETON, P.L., CAREY, F.A., STEELE, R.J., BARKER, N., CLEVERS, H., RIDGWAY, R.A., SANSOM, O.J., NÄTHKE, I.S. (2010) Spindle orientation bias in gut epithelial stem cell compartments is lost in precancerous tissue. Cel/ Stem Cel/6: 175-181.

RAMOS, A., GRÜNERT, S., ADAMS, J., MICKLEM, D.R., PROCTOR, M.R., FREUND, S., BYCROFT, M., ST JOHNSTON, D., VARANI, G. (2000) RNA recognition by a Staufen double-stranded RNA-binding domain. EMBO J19: 997-1009.

ROEGIERS, F., YOUNGER-SHEPHERD, S., JAN, L.Y., JAN, Y.N. (2001) Bazooka is required for localization of determinants and controlling proliferation in the sensory organ precursor cell lineage in Drosophila. Proc Nat/Acad Sci USA98: 14469-14474.

SATO, M., KOJIMA, T., MICHIUE, T., SAIGO, K. (1999) Bar homeobox genes are latitudinal prepattern genes in the developing Drosophila notum whose expression is regulated by the concerted functions of decapentaplegic and wingless. Development 126: 1457-1466.

SCHAEFER, M., PETRONCZKI, M., DORNER, D., FORTE, M., KNOBLICH, J.A. (2001) Heterotrimeric $G$ proteins direct two modes of asymmetric cell division in the Drosophila nervous system. Cel/107: 183-194.

SCHAEFER, M., SHEVCHENKO, A., SHEVCHENKO, A., KNOBLICH, J.A. (2000) A protein complex containing Inscuteable and the Galpha-binding protein Pins orients asymmetric cell divisions in Drosophila. Curr Bio/10: 353-362.

SEERY, J.P., WATT, F.M. (2000) Asymmetric stem-cell divisions define the architecture of human oesophageal epithelium. Curr Bio/10: 1447-1450.

SEUGNET, L.; SIMPSON, P.; HAENLIN, M. (1997) Requirement for dynamin during Notch signaling in Drosophila neurogenesis. Dev Bio/192: 585-598

TONG, X., ZITSERMAN, D., SEREBRIISKII, I., ANDRAKE, M., DUNBRACK, R., ROEGIERS, F. (2010) Numb independently antagonizes Sanpodo membrane targeting and Notch signaling in Drosophila sensory organ precursor cells. Mol Biol Cel/21: 802-810.

VERVOORT, M., ZINK, D., PUJOL, N., VICTOIR, K., DUMONT, N., GHYSEN, A., DAMBLY-CHAUDIÈRE, C. (1995) Genetic determinants of sense organ identity in Drosophila. regulatory interactions between cut and poxn. Development 121 : 3111-3120.

WIRTZ-PEITZ, F., NISHIMURA, T., KNOBLICH, J.A. (2008) Linking cell cycle to asymmetric division: Aurora-A phosphorylates the Par complex to regulate Numb localization. Cel/135: 161-173.

YOUSEF, M.S., KAMIKUBO, H., KATAOKA, M., KATO, R., WAKATSUKI, S. (2008) Miranda cargo-binding domain forms an elongated coiled-coil homodimer in solution: implications for asymmetric cell division in Drosophila. Protein Sci17: 908-917

ZHANG, J., NIU, C., YE, L., HUANG, H., HE, X., TONG, W.G., ROSS, J., HAUG, J., JOHNSON, T., FENG, J.Q., HARRIS, S., WIEDEMANN, L.M., MISHINA, Y. $\mathrm{LI}, \mathrm{L}$. (2003) Identification of the haematopoietic stem cell niche and control of the niche size. Nature 425: 836-841. 


\section{Further Related Reading, published previously in the Int. J. Dev. Biol.}

Ontogeny of an adventurous mind: the origin of Antonio García-Bellido's contributions to developmental genetics Alain Ghysen

Int. J. Dev. Biol. (2009) 53: 1277-1290

Preface. Developmental Morphodynamics - bridging the gap between the genome and embryo physics Lev V. Beloussov and Richard Gordon Int. J. Dev. Biol. (2006) 50: 79-80

The origin and evolution of the nervous system Alain Ghysen

Int. J. Dev. Biol. (2003) 47: 555-562

From hematopoietic stem cells to neural stem cells

S Bonilla, P Alarcon, R Villaverde, P Aparicio, A Silva, S Martinez

Int. J. Dev. Biol. (2001) 45: S67-S68

Asymmetry and cell fate in the Drosophila embryonic CNS

S Fuerstenberg, J Broadus and C Q Doe

Int. J. Dev. Biol. (1998) 42: 379-383

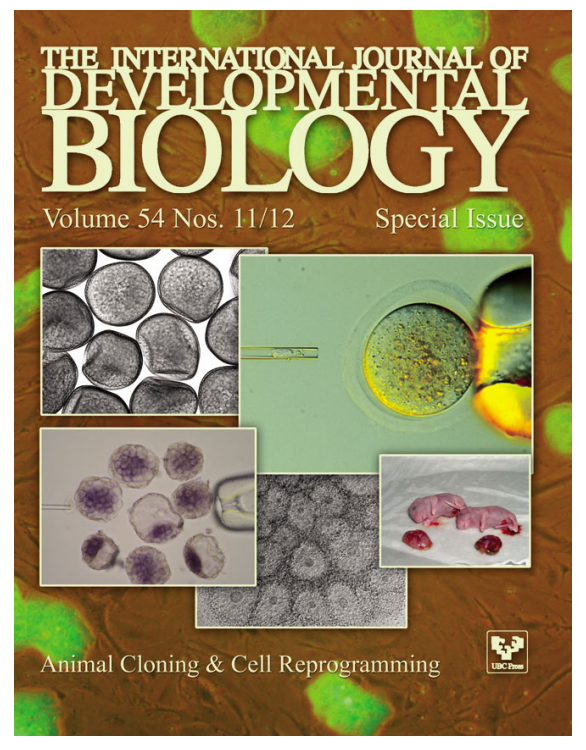

5 yr ISI Impact Factor $(2009)=3.253$

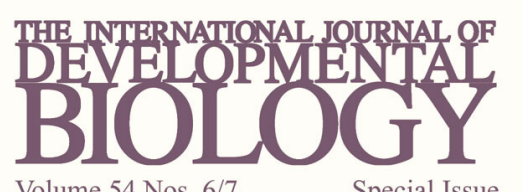

Volume 54 Nos. $6 / 7$

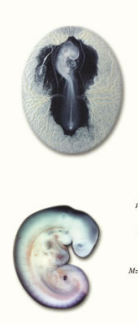

Developmental Hematopoiesis

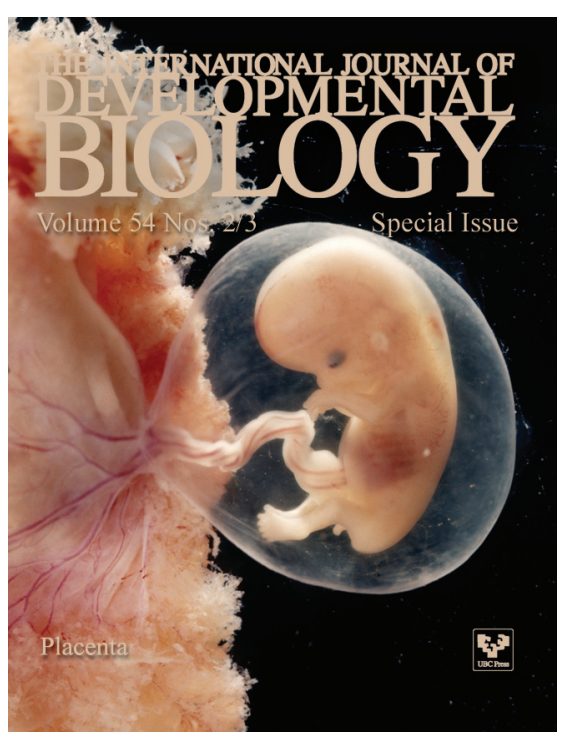

